\title{
Sculpture Bearing "Meanings" Tradition of French Classical Sculpture and Modern Sculpture of Sichuan Province
}

\author{
Xijun Deng ${ }^{1,2, *}$
}

${ }^{1}$ College of Literature and Journalism, Sichuan University, Chengdu, Sichuan, China
${ }^{2}$ School of Movie and Media, Sichuan Normal University, Chengdu, Sichuan 610064, China
${ }^{*}$ Corresponding author. Email: 279263855@ qq.com

\begin{abstract}
The so-called sculpture bearing "meanings" refers to a sculptural language system that vividly reproduces nature with full physical space, heavy volume, rigorous realistic skills, precise anatomical structure and proportion of shapes. This is an aesthetic law centered on the theme and completely faithful to the natural body structure. An important criterion for people to judge the pros and cons of classical sculpture language is the degree of conquest of media technology (shape, space, volume, anatomy, proportion, color, etc.). The higher the degree of conquest is, the more imitated is, the better the sculptor will be. In contrast to modernist sculpture, the tradition of classicist sculpture is not to express "objects" but to reproduce nature to the greatest extent. Sichuan modern sculpture introduced this teaching system to China through the Sculpture Department of the Academy of Fine Arts of Paris. Its basic language paradigm is the French classical sculpture tradition. This is the transformation of Sichuan modern sculpture from "Theodizee" to "Anthrodizee". The specific performance is the change of sculpture content (theme) from "God" to "man", that is, modern sculpture begins to take "man" as the object of molding, which is an important sign of the difference between modern sculpture and ancient sculpture. As the representative of sculptors from other provinces, Liu Kaiqu immerses himself in the atmosphere of Sichuan culture. At the same time, there is the collision and blending of new sculpture and the sculpture tradition of Sichuan Province. His sculpture works created in Chongqing and Chengdu for decades have injected fresh blood into the modern process of Sichuan sculpture and composed a new chapter in the process of Sichuan modern sculpture.
\end{abstract}

Keywords: classical sculpture, sculpture language, media language, sculpture of Sichuan Province

\section{INTRODUCTION}

The first generation of Chinese sculptors, who introduced the French classical sculpture tradition to China through the Sculpture Department of Academy of Fine Arts of Paris, became the origin of modern sculpture in Sichuan. For Sichuan and even China, this is the transformation of sculpture from "Theodizee" to "Anthrodizee". Its specific performance in sculpture is the change of sculpture content (theme) from "God" to "man". That is to say, modern sculpture begins to take "human" as the object of molding (taking celebrities, events, wars, farm workers, animals and people's livelihood in various fields as the themes), which is an important sign of the difference between modern

*This article is supported by staged results of the general project of "humanities and social sciences of Sichuan Provincial Department of Education" - Research on Game and Animation Derivative Design Material Language"(15SB0025). sculpture and ancient sculpture.

\section{THE ENLIGHTENMENT OF IMAGES: THE INTRODUCTION AND RECEPTION OF FRENCH CLASSICAL SCULPTURE}

According to the literature, Liu Kaiqu returned to Shanghai in 1933, visited Cai Yuanpei at the Central Research Institute, and met Lu Xun. Lu Xun talked to Liu Kaiqu, "in the past, there only has Bodhisattva sculpture. Now it's the turn to make the sculpture of human beings." Liu Kaiqu did some research. At that time, people generally believed that "sculpture refers to Buddha, Bodhisattva or longevity statue". "Because I used clay to make statues, my neighbors called me a worker of making mud Bodhisattva. The police regarded me as a vendor who made a living by this, and asked me to register. No one asked me to make the sculpture for a living person, and people believe that I 
would take away the soul of the living person". ${ }^{1}$ That is to say, the people regarded the realistic sculpture art as "the technique of captivating souls" at that time. It can be seen that the first thing to be solved in the introduction of new sculpture is the artistic problem of sculpture itself. At the same time, it expresses a position of cultural value, that is, with the enlightenment of sculpture images, the rationality, science and freedom are used to break the superstition and blind obedience of religious theology, so as to embark on the road of modernization.

Cai Yuanpei, the pioneer of modern art education in China, first paid attention to sculpture art and put sculpture major into the system of modern art education for the first time. Cai Yuanpei studied in Europe in June 1907. When there were endless schools of concrete and abstract expression in the field of French art, Cai Yuanpei advocated learning realistic sculpture art. In his opinion, there are four standards of sculpture: "the first is symmetry, the length of each part is proportional, which is not against the natural state; the second is the work of improvement, which is impeccable; the third is to be natural, without axe and chisel; and the fourth is to be vivid and graceful, which is in line with the common practice of running a school." ${ }^{2}$ The discussion of new ideas, the application of new culture, the collapse of old orders, and the attack on the old order are aimed at all fields of traditional culture, which also caused great discussion of fine arts, that is, "art revolution". In fact, the "art revolution" advocated western realistic techniques. It believed that "the decline of modern Chinese painting is caused by the fallacy of painting theory" 3 . It opposed the four skills of copying ancient painting of "practicing", "copying", "imitating" and "depicting" of Chinese painting. Chen Duxiu thought that "if we want to improve Chinese painting, we must first change the paintings". In order to improve Chinese paintings, it is necessary to adopt the realistic spirit of foreign paintings. What's the reason? For example, only by using realism can the literati adopt the technology of the ancients, develop their own genius, draw their own paintings, and do not fall into the pattern of the ancients. ${ }^{4}$ And they can strongly advocate the fine brushwork of depicting in the northern and southern Song Dynasty and the early Yuan Dynasty, and oppose

Zheng Chao. "History of Sculpture: 70 Years of Sculpture Department of China Academy of Art", Hangzhou: China Academy of Art Press, 1998, p70.

Liu Kaiqu. "Remembrance of Sculpture Art", "Cultural Education of Old China" edited by the CPPCC National Committee of Literature and History, Hefei: Anhui People's Publishing House, 2000, p 243

Cai Yuanpei. "Anthology of Cai Yuanpei", Beijing: Peking University Press, 1983, p59.

Lang Shaojun, Shui Tianzhong. "Anthology of Chinese Art in the Twentieth Century", Volume 1, Shanghai Painting and Calligraphy Press, 1999, p21. the blind worship of metaphor. Obviously, according to the above analysis, it is found that those western modern art thoughts with considerable power and profundity have not been accepted by the society and sculpture circles in the repeated debate, while the western realism advocated by $\mathrm{Xu}$ Beihong has been popular. The essence of the "art revolution" in the early 20th century is the spirit of "going into the society". Sculpture is regarded as an art style with the purpose of social revolution under utilitarianism. As a result, realism becomes a kind of "body".

\section{SCULPTURE AS THE MEDIUM: THE AESTHETIC ESSENCE OF FRENCH CLASSICAL TRADITIONAL SCULPTURE}

"Human body - sculpture - modeling — casting", as the shaping system of classical sculpture language, is really an art to reproduce the human body through the form and space (in painting, it refers to color block, block surface and texture). In the classical language system, Professor $\mathrm{Wu}$ Xingming believes that the "classical sculpture focuses not on 'objects', but on themes. Object is only the intermediary presenting the theme and content. The more it disappears in the work, the better the work will be completed". 5 That is to say, the media of classical sculpture exists as a tool. The media completely melts in the reappeared sculpture theme, and has no independent aesthetic value. Obviously, the media of classical sculpture conveys the plot of the story with the literary meaning. Therefore, it is necessary to make an in-depth analysis of the characteristics of its classical sculpture language and its sculpture-making techniques, so as to clarify how modern sculpture of Sichuan Province imitates the French classical sculpture language.

First of all, the basic language of French classical sculpture is characterized by rigorous realistic skills and full body features. Most of them express the theme of heroism, emphasize science and rationality, standard composition, and ignore subjective emotional expression. French classical sculpture should not only make the sculpture look true (realistic), but also look beautiful. For example, Myron's "Discobolus" and replica sculpture "Dancing Pan" began to try the sculpture language of body rotation in space, and systematically denied the sculpture language of ancient times. Specifically, through the artist's intentional distortion and rotation of the three large spatial structures of head, neck and chest, the "Dancing Pan" has a spatial form that must be viewed around the sculpture. On the other hand, the classical sculpture has always avoided the symmetrical and stable technique. As the left side is rotated and squeezed, "it adopts

Lang Shaojun, Shui Tianzhong. "Anthology of Chinese Art in the Twentieth Century", Volume 1, Shanghai Painting and Calligraphy Press, 1999, p29. 
zigzag lines. The right side is closed, and the left side is open"6, which forms a continuous arc from the position of the chest, neck and fossa of the sculpture to the position of the pubic bone. It is through the shaking space tension formed between the front body orientation and the side legs to capture the moment before Pan dancing, reflecting the elegance, sweetness and strength.

Secondly, from the perspective of sculpture production techniques, the more complex sculpture works use the "three-dimensional fixed-point method". In the ancient and classical times, the Greek made stone statues of schematic analysis. The sculptors first used clay to create a clay model, and then measured the marble outside the sculpture according to the "point positioning" method. "3D" is to set three axes ( $\mathrm{x}$-axis, $\mathrm{Y}$-axis and Z-axis) in the space, corresponding to each point in the space ( $\mathrm{x}$-axis measures the width, $\mathrm{Y}$-axis measures the height, and $\mathrm{z}$-axis measures the depth). Specifically, the clay model is in the same modeling system with the "three-dimensional fixed-point method". The highest point or lowest point of a part of the sculpture is measured by the tool, and then the same ups and downs are marked on the stone. "The sculptor will cut off the redundant part and leave the corresponding point." 7

Finally, from the perspective of the artistic techniques of classical sculpture, it emphasizes the shaping of "volume" and the expression of body language. "Volume" refers to the size and mass of the sculpture itself. And it is the entity occupying threedimensional space, not the edge outline of the object. Rodin, a classicist sculptor, believes that the deep modeling, and "the assumption that the form is directly directed at you, and that all life flows from a central point, expanding from the inside out" ${ }^{8}$ are the best interpretation of the spatial language of the form. Classical sculpture is based on literary texts or myths and legends. Then, the most direct and powerful way of expression is certainly to strengthen body language, using body movements, different figures' body posture and demeanor to convey the emotion in the literary sense. According to the above analysis of the language features, production methods and the emphasis on the shaping of "volume" of classical sculpture, French classical traditional sculpture is a medium to convey literary significance, and the sculpture materials themselves have no independence.

6 Wu Xingming. "On the Philosophical Sense of AvantGarde Art - Focusing on "objects", Literature and Art Studies, Issue 1, 2014, p13.

(British) Woodford. S. "Ancient Greek and Roman Art" (The Twentieth Century), translated by Qian Chengdan, Nanjing: Yilin Press, 2009, p16.

(British) Woodford. S. "Ancient Greek and Roman Art" (The Twentieth Century), translated by Qian Chengdan, Nanjing: Yilin Press, 2009, p137.

\section{THE RISE OF MODERN SCULPTURE OF SICHUAN PROVINCE: LIU KAIQU'S SCULPTURE COMMUNICATION IN SICHUAN PROVINCE}

As a representative of sculptors from other provinces, Liu Kaiqu not only immerses himself in the atmosphere of Sichuan culture, but also brings about the collision and blending of new sculpture and Sichuan sculpture tradition. Liu Kaiqu (who arrived in Chengdu at the end of 1938) has lived in Chongqing and Chengdu for nearly ten years, during which he has created four large-scale monument sculptures and dozens of sculpture works. These sculptures are different from Sichuan traditional sculptures. Liu Kaiqu has injected fresh blood into the modern process of Sichuan sculpture and composed a new chapter in the process of Sichuan modern sculpture. Its influence on early modern sculpture in Sichuan can be summed up in the following aspects:

First of all, the introduction of western traditional realistic sculpture language mode has opened the first step of Sichuan modern sculpture. Sichuan sculpture has changed from the mode of reflecting religious mythology to the expression of modern society and public life, which has promoted the change and progress of Sichuan sculpture language. "In terms of creation, Liu Kaiqu wants to try his best to make works not separated from social life, so that it can generally reflect the social life at that time". ${ }^{9}$ It can be seen that art works of different national styles can be created and produced by directly reflecting people's feelings, thoughts, artistic temperament and means of sculptors in the current society. Viewing the portrait works "female portrait" and "portrait of Bi Qi, President of West China Union University", the author has uncritical acceptance of western classical sculpture, especially since ancient Greece, Rome and the Renaissance. When creating "the nameless hero", he said: "I don't have a model, and I can't afford to hire a model. I run with a gun to shape the face of a hero." ${ }^{10}$ Based on the research of human anatomy and scientific proportion of real models, the super realistic modeling skills are strengthened. The decades of sculpture creation has changed the Sichuan sculpture from myth and longevity statue to the depiction of social life of the general public, which is fundamentally different from the traditional way of teaching and learning from teachers and apprentices.

Secondly, the emphasis on body and space language has promoted the development of ontology language of Sichuan sculpture, which is embodied in the method of

(French) Rodin. "The Theory of Rodin Art" (narrated by Rodin and noted by Gesell), translated by Shen Qi, Wu Zuoren, Beijing: People's Fine Arts Publishing House, 1978

10 Sculpture Department of China Academy of Art. "Sculpture: 70 Years of Sculpture Department of China Academy of Art", Hangzhou: China Academy of Art Press, 1998, p72. 
"moving people directly with one form and one volume" 11 . That is to say, sculpture is an art that occupies space. Different from two-dimensional plane painting, sculpture does not use background and color to complete the visual effect of art. It uses concise body language and materials to "express the depth and breadth of objects, so some people say that sculpture is a solidified poem" ${ }^{12}$. The language of sculpture, including space, shape, weight, texture of materials and so on, converges into the whole sculpture. In the specific molding process, the intentional retention of strokes (scratches) like paintings contains the feelings of sculptors and enriches the language of sculpture. Unfortunately, the language of classical sculpture (space, form, sense of weight, texture of materials, etc.) exists passively as a dependency of literary meaning.

Thirdly, the reflection on the theory of stereoscopic photography is another important influence of Liu Kaiqu on the language of modern sculpture in Sichuan. Liu Kaiqu, a sculptor, has repeatedly stressed that "we should not make images just for the sake of making images. I think it's a fax, a stereo...It takes pictures for people to remember, and leaves materials for history. However, it is not the thing that guides people to create lofty ideal sculpture art."13 It can be seen from this that although the classical method of sketching has been introduced into the classroom, still life, models, gypsum, labor scenes, etc. have become the objects of sculpture. However, sculpture not only stays on the "true" skills, but also pays attention to the feelings of shaping objects. In this way, sculptors can constantly enhance the observation ability and improve the skills of shaping. At the same time, Liu Kaiqu believes that there is a clear language boundary between sculpture and literature. "Some actions and moods or situations are described in words, which can be clear. However, they can't be expressed in image language, which can't bring up visual beauty in modeling, so it is not suitable to use sculpture art to reflect" ${ }^{14}$. This is a preliminary reflection on the boundaries among sculpture language, literature language and painting language, which has a positive impact on the exploration of self-discipline of modern language of Sichuan sculpture in the 1980s.

11 Sculpture Department of China Academy of Art. "Sculpture: 70 Years of Sculpture Department of China Academy of Art", Hangzhou: China Academy of Art Press, 1998, p86.

12 Yang Lizhou. "The Pioneer of Chinese Modern Sculpture: Liu Kaiqu", "New Cultural Historical Materials", No. 1, 1995, p33.

13 Liu Mina. "Giving Life to Stones - Professor Liu Kaiqu Talking about Sculpture", "Popular Tribune", Issue 07, 1992.

14 Sculpture Department of China Academy of Art. "Sculpture: 70 Years of Sculpture Department of China Academy of Art", Hangzhou: China Academy of Art Press, 1998, p64-p65.

\section{CONCLUSION}

Under the specific historical environment, the early modern sculpture in Sichuan Province has experienced the initial overall acceptance and absorption of western traditional realistic sculpture language mode, the exploration of sculpture ontology language and the preliminary reflection of "three-dimensional creation theory". On the basis of rigorous and accurate western realism, combined with the simple and bright line, volume and modeling techniques of Sichuan sculpture tradition, it initially constructed unique modern sculpture mode of Sichuan Province. However, this kind of sculpture language exists as a media in a sense, and has no independent aesthetic value. However, the heterogenous culture outside Sichuan Province has given the sculptors in other provinces unique visual and value standards. Due to the transitional nature of society and the trend of cultural exchange, modern sculptors in Sichuan have not yet fully digested and absorbed the tradition of French realist sculpture language. Once again, the Soviet Union's social realist monument, as a "heterogeneous culture", has made the transformation, collision and blending for the sculptors in Sichuan Province.

\section{References}

[1] Zheng Chao. "History of Sculpture: 70 Years of Sculpture Department of China Academy of Art", Hangzhou: China Academy of Art Press, 1998. (in Chinese)

[2] CPPCC National Committee of Literature and History. "Cultural Education of Old China", Hefei: Anhui People's Publishing House, 2000. (in Chinese)

[3] Cai Yuanpei. "Anthology of Cai Yuanpei", Beijing: Peking University Press, 1983. (in Chinese)

[4] Lang Shaojun, Shui Tianzhong. "Anthology of Chinese Art in the Twentieth Century", Volume 1, Shanghai Painting and Calligraphy Press, 1999. (in Chinese)

[5] (British) Woodford. S. "Ancient Greek and Roman Art" (The Twentieth Century), translated by Qian Chengdan, Nanjing: Yilin Press, 2009. (in Chinese)

[6] (French) Rodin. "The Theory of Rodin Art" (narrated by Rodin and noted by Gesell), translated by Shen Qi, Wu Zuoren, Beijing: People's Fine Arts Publishing House, 1978. (in Chinese)

[7] Sculpture Department of China Academy of Art. "Sculpture: 70 Years of Sculpture Department of China Academy of Art", Hangzhou: China Academy of Art Press, 1998. (in Chinese)

[8] Yang Lizhou. "The Pioneer of Chinese Modern Sculpture: Liu Kaiqu", "New Cultural Historical Materials", No. 1, 1995. (in Chinese)

[9] Liu Mina. "Giving Life to Stones - Professor Liu Kaiqu Talking about Sculpture", "Popular Tribune", Issue 07, 1992. (in Chinese)

[10] Wu Xingming. "On the Philosophical Sense of Avant-Garde Art - Focusing on "objects", Literature and Art Studies, Issue 1, 2014. (in Chinese) 